\title{
Erratum to: Who Benefits Most from a University Degree?: A Cross-National Comparison of Selection and Wage Returns in the US, UK, and Germany
}

\author{
Renee Reichl Luthra ${ }^{1} \cdot$ Jennifer Flashman $^{2}$
}

\section{Erratum to: Res High Educ DOI 10.1007/s11162-017-9451-5}

The affiliation of second author Jennifer Flashman, "Yammer Microsoft" is unfortunately tagged as third author.

This article has only two authors, Renee Reichl Luthra and Jennifer Flashman. The second author is affiliated with "Yammer Microsoft".

The original article has been corrected.

The online version of the original article can be found under doi:10.1007/s11162-017-9451-5.

Renee Reichl Luthra rrluthra@essex.ac.uk

1 Department of Sociology, University of Essex, Wivenhoe Park, Colchester CO43SQ, UK

2 Yammer Microsoft, San Francisco, USA 